W Child - "Wittgenstein and Phenomenal Concepts”, in M. Campbell and M. O’Sullivan, eds, Wittgenstein and Perception, Abingdon: Routledge, pp. 84-103.

\title{
Wittgenstein and Phenomenal Concepts
}

\author{
William Child
}

Many philosophers think that there are phenomenal concepts: distinctive ways of thinking of experiences or sensations that can be grasped only by those who know what it is like to have those experiences or sensations. What light does Wittgenstein's philosophy throw on this idea?

In the literature, phenomenal concepts are often deployed for explicitly antiWittgensteinian purposes. Brian Loar and Christopher Peacocke, for example, both appeal to phenomenal concepts in arguing, against Wittgenstein, that a person can derive, from her own case, a concept of pain that can be applied to other people. ${ }^{1}$ And David Papineau and Katalin Balog argue that the existence of phenomenal concepts is inconsistent with Wittgenstein's arguments against a private sensation language. ${ }^{2}$ Against these and similar views, I shall argue for the unorthodox view that a Wittgensteinian approach to sensations and sensation language can accommodate a version of the idea that there are distinctive concepts of sensations that are available only to those who know what it is like to have those sensations. For those who are interested in Wittgenstein, that is an important corrective to much that has been thought about the nature of a Wittgensteinian approach to these matters. For those who are interested in phenomenal concepts, my discussion helps to identify exactly what the existence of such concepts does and does not involve.

\section{Phenomenal Concepts and Knowing What It's Like}

The idea of phenomenal concepts assumes a distinction between properties and concepts of those properties. For example, there is a property of pain; and there are various concepts, or ways of thinking, of that property. In particular, there is 'a distinctive way of thinking about the state of being in pain [that is] available to those who know what it is like to feel pain' (Peacocke 2009, 188). Consider someone who has the real condition, CIPA, 'which involves a congenital insensitivity to conditions that in normal subjects cause pain' (ibid., 177). Such a person 'never feels pain, and does not know what it would be like to experience pain'. That does not stop her thinking about the property of pain; she does have a concept of pain. But, on the phenomenal concept view, she cannot have the same concept of pain as the rest of us, who know what it is like to feel pain.

On this view, grasping the concept pain requires knowing what it is like to experience pain. ${ }^{3,4}$ But what does it take to know what it is like to feel pain? Many

\footnotetext{
1 See Loar 1997; Peacocke 2009 ch. 5. (Peacocke does not actually use the phrase 'phenomenal concept'. But his position clearly is a version of the phenomenal concept view.) For the Wittgensteinian views to which Loar and Peacocke are objecting, see e.g. PI §350. I do not think that the concept of pain that Loar and Peacocke identify is in fact derived 'from one's own case' in the sense that Wittgenstein was arguing against. The discussion of part 4 below is relevant to that point.

2 See Papineau 2011; Balog, 2009.

3 I shall use the phrase 'the concept pain' to pick out the distinctively phenomenal concept of pain. 4 In some passages, Peacocke prefers the formulation 'knows what it would be like to feel pain', to accommodate the possibility of someone who grasps the phenomenal concept of pain but has never
} 
philosophers think it involves the ability to imagine feeling pain. ${ }^{5}$ I follow Peacocke in taking a different view. For Peacocke, the key requirement is the ability to recognize a feeling as pain when one has it (and to recognize it non-inferentially, on the basis of the experience). And it is plausible to think that one can have that ability even if one cannot imagine pain. That echoes Wittgenstein's point that one can know what someone looks like in virtue of being able to mimic her face, without being able to imagine it (see PI $\S 450$ ). Wittgenstein would say the same thing about recognition: I count as knowing what someone looks like if I can recognize her face when I see it, even if I cannot imagine it. Indeed, Wittgenstein himself comes close to expressing precisely the view of knowing what an experience is like that I have in mind, in a discussion of knowing what sugar tastes like (see RPP II §§346-53). Knowing what sugar tastes like, he says, involves being able to recognize that taste when one tastes it; it does not require the ability to bring an image of the experience to consciousness. (For this last point, see especially RPP II §353.)

It is worth stressing that, on this view, what is essential for grasping the concept pain is not that one has in fact felt pain; it is that one knows what it is like to feel pain. Putting things that way makes room for the possibility of cases where someone who has never had experiences of a certain kind nonetheless knows what it would be like to have them, and vice versa. One example might be Hume's missing shade of blue. Hume's man has never experienced the missing shade of blue. But he knows what it would be like to experience it. Another example involves a familiar kind of science-fiction case. Suppose a molecule-for-molecule replica of me suddenly comes into existence. The replica itself has never yet felt pain. But, intuitively, he knows what it is like to experience pain; he will recognize pain as such when he feels it. ${ }^{6}$

It is also plausible that someone who has had experiences of a given kind might nonetheless fail to know what it is like to have them - because she cannot recognize such experiences when she has them again. The case of face-recognition again provides an analogy. A person with face agnosia may have seen someone many times but be unable to recognize him; she does not know what he looks like. Similarly, someone might have experienced sensations of a given kind - the tingling feelings caused by a mild electric shock, say - but be unable to recognize those sensations as tingling feelings when she has them again. In our sense, such a person does not know what it is like to have those sensations.

I said that, on the current view, knowing what it is like to feel pain requires the ability to recognize something as pain when one feels it, and to recognize it 'noninferentially, on the basis of the experience'. The proviso that one must recognize pain non-inferentially is required for the following reason. I have never had a migraine. And, intuitively, I do not know what it feels like to have a migraine. But it is plausible, given what I know about migraines, that if I were to have a migraine I could identify it as a migraine. So, it may seem, the ability to recognize something as a migraine when one has it is not sufficient for knowing what it is like to have a migraine. In a case like this, however, my identification of the experience as a migraine essentially depends on an inference: 'This must be a migraine because people with migraines feel sick, they see flashing lights, they want to stay in the dark etc.; and that is how it is for me.' Things

actually experienced pain herself. (For this possibility, see the text below.) For the sake of simplicity, I stick to the 'what it is like' formulation.

5 See e.g. Nemirow, Lewis.

6 Both these examples were suggested to me by Peacocke. For discussion of a case similar to Hume's, see Conee 1994. For a case related to the second example, see the discussion of Swamp Mary in Dennett 2007, 24-5. 
W Child - "Wittgenstein and Phenomenal Concepts”, in M. Campbell and M. O’Sullivan, eds, Wittgenstein and Perception, Abingdon: Routledge, pp. 84-103.

are different for someone who already knows what it is like to feel a migraine: her identification of her current experience as a migraine does not depend on any such inference; she identifies the experience as a migraine just on the basis of the experience itself.

Many recent discussions of phenomenal concepts have been motivated by an interest in defending physicalism. But that motivation is not universal: for one thing, some of those who think that there are phenomenal concepts reject physicalism. I shall not be concerned with the pros or cons of physicalism, or the pros or cons of appealing to phenomenal concepts in response to various anti-physicalist arguments. My focus is just on the nature of phenomenal concepts themselves, and their relation to Wittgenstein's view of sensation and sensation language.

2. 'Could someone who had never felt pain understand the word "pain”?' Can a Wittgensteinian view of sensations accept that there are phenomenal concepts? Consider the following passage from Philosophical Investigations:

Could someone who had never felt pain understand the word 'pain'? - Is experience to teach me whether this is so or not? - And if we say 'A man could not imagine pain without having sometime felt it', how do we know? How can it be decided whether it's true? (PI §315)

Wittgenstein asks whether someone who had never felt pain could understand the word “pain” (PI §315). There are two important differences between that question and the question we have introduced: whether someone who didn't know what it is like to feel pain could grasp the concept pain. First, Wittgenstein considers what is possible for someone who has never felt pain, rather than what is possible for someone who does not know what it is like to feel pain. Second, he is concerned with conditions for understanding a word, rather than conditions for grasping a concept. We can take these points in order.

On the first point, for present purposes I shall simply gloss over the difference between Wittgenstein's formulation ('someone who has never felt pain') and ours ('someone who doesn't know what it is like to feel pain'). For the reasons given in part 1 , it seems possible for someone to know what some kind of sensation feels like without having experienced it. But it is plausible that such cases rarely if ever arise - at least for relatively coarse-grained concepts like pain.

What of the second point? What is the relation between Wittgenstein's question about the conditions for understanding the word 'pain' and our question about the conditions for grasping the concept pain? That depends on the relation between words and concepts. On one view, there is a one-to-one correlation between words and concepts. The English word 'pain' expresses the concept pain; and anyone who understands the word 'pain' grasps the concept pain. On this view, whatever conditions there are for grasping the concept pain will equally be conditions for understanding the word 'pain'. So if grasping the concept pain requires knowing what it is like to feel pain, then so does understanding the word 'pain': and vice versa. An alternative view is that we should individuate concepts more finely than words. On this view, the word 'pain' is not tied to any particular way of thinking of pain. That makes room for possibilities of the following kind. We, who know what it is like to feel pain, use the word 'pain' to express a concept of pain that is available only to those who know what pain feels like. People with CIPA, who do not know what it is like to feel pain, use the word 'pain' to express some other way of thinking of pain. They understand the word 'pain' as well as we do; they just use it to express a different concept of pain. 
Suppose that, like Wittgenstein, we phrase our question in terms of the conditions for understanding the word 'pain'. And suppose we think it is possible for someone to understand the word 'pain' without knowing what it is like to feel pain. That is consistent with thinking that there is a distinctive phenomenal concept of pain, provided we accept: first, that concepts can be individuated more finely than words, so that two people can understand the same word but use it to express different concepts; and second, that as well as the concept of pain that is grasped by the person with CIPA, there is another concept of pain, grasp of which requires knowing what it is like to feel pain.

With those preliminaries in mind, we can return to PI §315. Wittgenstein is concerned in this section to make the following two points. (I put these points in terms of concepts rather than words.) First, it is not an empirical matter whether or not grasp of the concept pain requires knowing what it is like to feel pain. Second, grasping the concept pain does not involve or require the ability to imagine pain. But the advocate of phenomenal concepts accepts both points. On the phenomenal concept view it is, as Wittgenstein would put it, a grammatical truth that grasp of the concept pain requires knowing what it is like to feel pain: someone who did not know what it is like to feel pain would not count as grasping the concept pain. And the phenomenal concept view, as we have explained it, agrees with Wittgenstein that grasping the concept of pain does not involve imagining pain. So far as I can see, then, nothing Wittgenstein says in $\S 315$ directly challenges the idea that there are concepts of experience that are available only to those who know what it is like to have those experiences.

Wittgenstein certainly thinks that there are some concepts of experience that can be grasped without knowing what it is like to have the relevant experiences. He remarks, for example: 'I [never] have feelings of an invisible presence; other people do, and I can question them about their experiences' (PPF vii §52 [PI II vii p. 184]). That is to say, I can understand the phrase 'feelings of an invisible presence', and have a concept of such feelings, without ever having had those feelings myself (and so, we are assuming, without knowing what it is be like to have them). ${ }^{7}$ It is clear that Wittgenstein would say the same about many other mental concepts. But would he accept that there are also concepts of experience that are available only to those who do know what it is like to have those experiences?

\section{3. $\quad$ Electric Shocks and Tingling Feelings}

PPF §370 (PI II xiii p. 231) mentions a case where it seems very plausible to accept that there are two different ways of thinking of a kind of experience: one that requires knowing what the experience is like; the other that does not. The context is Wittgenstein's discussion, and rejection, of the idea that remembering has a distinctive experiential content. He writes:

Would this situation be conceivable: for the first time in his life someone remembers something and says: 'Yes, now I know what "remembering" is, what it feels like to remember' - - How does he know that this feeling is 'remembering'? Compare: 'Yes, now I know what "tingling”' is' (he has perhaps had an electric shock for the first time). - Does he know that it is memory because it is caused by something past? And how does he know what the past is? After all, a person learns the concept of the past by remembering (PPF xiii §370).

7 See RPP I 120 for another example: 'The feeling of having been in just the same situation before. I have never had this feeling’ (RPP I 120). Yet Wittgenstein certainly has a concept of this feeling. 
Wittgenstein's view, I think, is this. It is not a genuine possibility that someone might remember for the first time in his life, and thereby know what it feels like to remember. But it is a genuine possibility that someone could have an electric shock for the first time and thereby come to know what tingling is; what it feels like to have tingling sensations. In this latter case, the subject already has a way of picking out the sensation of tingling: he can think of it, say, as the sensation one has when one has a mild electric shock. Then he has an electric shock for the first time; he experiences the tingling sensation for the first time. At that point he can truly say, or think, 'Now I know what tingling is; what it feels like to have an electric shock. ${ }^{8}$ And, though Wittgenstein does not put it this way, it seems reasonable to say that the person is now in a position to think of the sensation of tingling in a new way: a way that draws on his own experience of tingling sensations.

To underline this last point, imagine an extension of Wittgenstein's thought experiment. Someone knows that electric shocks cause tingling sensations. She has never had an electric shock and never felt these tingling sensations. Nonetheless, she does have a concept of the tingling sensations. After all, she can discuss such sensations with other people; she might even use their occurrence in others as a way of diagnosing neurological conditions. Then we give her a series of electric shocks, without telling her that that's what we are doing. She experiences the distinctive tingling feelings and, perhaps with the encouragement of others who know the set-up, she learns to classify them as ' $\Phi$ sensations'. So she now has two ways of thinking about the tingling sensations: on the basis of her knowledge that electric shocks cause tingling sensations; and on the basis of her experience of tingling sensations themselves. And these seem genuinely distinct ways of thinking; the discovery that her $\Phi$ sensations are tingling sensations is genuinely illuminating. ${ }^{9}$

One difference between the original thought experiment and this extension is the following. As I described the original case, the subject knows from the outset that the sensation he is having for the first time is the feeling of tingling: he knows that his new way of thinking of the feeling of tingling picks out a sensation that he can already individuate in a different way (e.g. as the sensation that is typically caused by a mild electric shock). In the extended thought experiment, things are different. When the subject learns to classify the new feelings as ' $\Phi$ sensations', she is as far as she is concerned learning to identify a kind of sensation for which she has no prior concept. So her mastery of the concept $\Phi$ sensation does not depend on her prior grasp of any concept of tingling sensations or on knowledge of the association between tingling sensations and electric shocks. But this feature of the extended case seems unobjectionable from a Wittgensteinian point of view. Wittgenstein does not deny that someone can acquire a concept of a kind of sensation without having a prior concept of exactly that sort of sensation. And, from the subject's point of view, that is just the situation of the person who acquires the new concept $\Phi$ for a kind of sensation that she has never felt before. (I will return to this issue at the end of the next section.)

\section{4. $\quad$ Phenomenal Concepts and Private Language}

8 I said above that it is not sufficient for knowing what tingling feels like that one has in fact experienced tingling feelings; one must be able to identify a sensation as a case of tingling when one feels it again. It seems plausible that the person who feels tingling for the first time could acquire the requisite ability from the first experience of tingling, even if it takes more than one occasion to demonstrate (to himself as well as others) that he has acquired it.

9 I discuss this Fregean criterion for difference of concepts in section 9 below. 
I have suggested that Wittgenstein can accept that there is a distinctive concept of tingling sensations that is available only to those who know what it is like to experience them. It might be objected that such a concept would be inconsistent with Wittgenstein's views, because it commits us to the possibility of a private sensation language. ${ }^{10}$ But the objection is mistaken; there is no such commitment.

The target of the discussion of private language in Philosophical Investigations and elsewhere is a view of sensations on which the identity conditions of sensationtypes are completely independent of any links to external circumstances or behaviour. For the case of colour experience, for instance, what Wittgenstein is arguing against is the view that the word 'red' 'signifies something "confronting us all”, and that everyone should really have another word, besides this one, to signify his own impression of red' (PI §273); or again, 'that one uses a word to mean at one time the colour known to everyone - and at another time the "visual impression" which I am getting now' (PI §277). Against that view, he argues that there is no way of individuating the kind of experience one has when something looks red except in a way that ties the character of the experience to the objective circumstance of seeing something red. I can certainly have such an experience even though I am not seeing anything red; it can look to me as if there is something red in my field of vision even if there isn't. But, Wittgenstein insists, that does not commit us to the idea that experiences have phenomenal characters whose identity conditions are entirely independent of all links to external circumstances, physiology, or behaviour; nor, a fortiori, does it commit us to the possibility of concepts that pick out such phenomenal characters.

From Wittgenstein's point of view, however, there is nothing problematic about using a word to pick out the sensation of tingling; the identity conditions of that sensation are (as he might put it) 'tied up with' the objective circumstance of having an electric shock; that a given sensation is an instance of tingling is inseparable from that link to external circumstances. That is compatible with allowing that I can, on occasion, have the sensation of tingling without having an electric shock: it can feel to me just as it does when I am having an electric shock even if I am not having an electric shock; and vice versa. In allowing that, we are not committing ourselves to the view of sensations that Wittgenstein is arguing against in the private language sections: the view that sensations have a 'phenomenal character' that floats free of any link to external circumstances or behaviour.

What I have just said about the feeling of tingling and its tie to the objective circumstance of having an electric shock mirrors what Wittgenstein says about the manometer in PI §270. Wittgenstein there rejects a particular model of the relation between a sensation and an associated physiological condition. The rejected model is this:

I start by introspectively identifying a distinctive kind of sensation, S. The sensation's identity conditions are a matter of its intrinsic, introspective character; and that is entirely independent of any links to behaviour or physiological state. So 'S' is, in Wittgenstein's sense, a private sensation word. Then I discover an empirical correlation between the occurrence of S-type sensations and rises in my blood pressure. I can then use the occurrence of an Stype sensation as a way of telling that my blood pressure is rising. But whether or not a given sensation is an S-type sensation remains a matter solely of its intrinsic character; it has nothing to do with any association between S-type sensations and the objective circumstance of my blood pressure rising.

10. For this suggestion, see Balog 2009, 298; Papineau 2011, 179-82. 
W Child - "Wittgenstein and Phenomenal Concepts”, in M. Campbell and M. O’Sullivan, eds, Wittgenstein and Perception, Abingdon: Routledge, pp. 84-103.

The model Wittgenstein accepts is this:

I have a way of telling that my blood pressure is rising without using any apparatus. This way of telling does not involve a mere groundless but reliable hunch: I really do experience something when my blood pressure rises. And when I write down ' $\mathrm{S}$ ' in my diary, I am not just noting a rise in my blood pressure; I am noting the occurrence of a sensation. The identity conditions of these S-type sensations are tied to the objective circumstance of my blood pressure's rising; what an S-type sensation is is the feeling of my blood pressure's rising. But it is compatible with that to suppose that, on occasion, I might have an S-type sensation without my blood pressure actually rising; and vice versa. ${ }^{11}$

The parallel view seems right for the case of the tingling sensations. Having an electric shock is not merely a physical and physiological phenomenon; a normally-functioning person who is given a mild electric shock really does feel something; she has a sensation. There is a difference between knowing what it is like to have those tingling feelings and not knowing it. And there is a way of thinking of the tingling feelings that is available only to those who know what they feel like. We can accept all that without committing ourselves to the possibility of a private language, or to anything else that Wittgenstein argues against in the private language sections.

In a recent paper, David Papineau argues for a different view. He agrees that the experiences, feelings and sensations picked out by phenomenal concepts are 'public objects' in Wittgenstein's sense. So there is no Wittgensteinian prohibition on our having words that pick them out. But, he thinks:

limitations on what kinds of things can be referred to [are] just one part of the private language argument. It also places strong further requirements on the way such reference may be secured in the first place (Papineau 2011, 181). In particular, Papineau thinks, it is part and parcel of the idea of a phenomenal concept that a person can establish a phenomenal concept of a type of experience by exactly the kind of one-off, introspective ostension that Wittgenstein aims to discredit. He offers the following thought experiment, which has essentially the same structure as our extension of Wittgenstein's thought experiment about tingling sensations. Marianna, like Frank Jackson's Mary, has lived her life in a black-and-white environment. Now

11 PI §270 is a complex passage. I would make two points about my reading of the passage. (i) I said that, when I write down ' $\mathrm{S}$ ' in my diary, I am not just noting a rise in my blood pressure; I am noting the occurrence of a sensation. But why should we say that? Wittgenstein writes: 'What reason do we have for calling "S" the name of a sensation? Perhaps the kind of way this sign is employed in this languagegame.' There could be a case similar to the one that Wittgenstein describes, but where ' $\mathrm{S}$ ' really is a word for a physiological condition, not a word for a sensation. It cannot be determined just from my diary entries whether ' $S$ ' is a word for a physiological condition (my blood-pressure's rising) or a word for a sensation (the feeling of my blood-pressure's rising). What disambiguates the word are features of the rest of its use: e.g. whether ' $S$ but my blood-pressure is not rising' could be true; whether ' $S$ ' could be true of someone who is unconscious; and so on.

(ii) It might be thought that, contrary to what I have said, the first paragraph of $\$ 270$ concedes that sensations are individuated in a way that is independent of the objective circumstance of one's blood pressure rising. For it might seem that Wittgenstein accepts that the character of my sensations could differ independently of changes in my blood pressure, and uses that fact to argue that, when I use the word ' $\mathrm{S}$ ', what I am recognizing is the presence of the physiological state rather than the presence of any sensation. I think that is a misreading. Wittgenstein's line of thought is this. If sensations were individuated in a way that was wholly independent any links to physiology or behaviour, then my word ' $S$ ' would not be the name of a sensation. But the right conclusion is not that ' $S$ ' is not a sensation-word. It is, rather, that sensations are not individuated in that way: they are individuated a way is tied to objective circumstances; and ' $\mathrm{S}$ ' is a word for a sensation, individuated in that way. (For the same style of argument, which is open to the same kind of misreading, see PI §293.) 
she is shown a piece of red paper. For the first time, she has an experience of red: she knows that this is a new experience; but she does not know what kind of experience it is. ${ }^{12}$ Papineau writes:

It certainly looks as if Marianna can coin a new concept $\Psi$, to refer to the kind of phenomenal property that has just been instantiated in her. Thus she might think, after having the experience, I will have $\Psi$ again today, or Everybody else I know has had $\Psi$ before. And these certainly look like thoughts in good standing, in that they will turn out to be true or false, even though Marianna may not yet know which. So $\Psi$ in turn must itself be a concept in good standing, given that it can be so used to form truth-evaluable thoughts (Papineau 2011, 176).

Similarly, Papineau says, Marianna can coin a new word, 'senso', to express the concept $\Psi$. But, he argues, on Wittgenstein's view it ought to be impossible for anyone to set up a word or a concept in this way.

[Wittgenstein] would object that at the point where Marianna coins [the term 'senso' and the concept $\Psi$ ], she set up no possibility of any public checks on her future usage - there is nothing in what she has done that will afford anybody else a potential way of checking whether she is using these terms with the same meaning in future (Papineau 2011, 181).

But, Papineau thinks, it is evident that Marianna would in fact be 'able to coin a term with a definite meaning as soon as she has had her new experience'. So 'Wittgenstein is ... setting the bar for meaningfulness too high' (Papineau 2011, 182).

How should we respond to Papineau's argument? As Papineau says, what the word 'senso' picks out is the experience of seeing something red. So it does not belong to a private sensation language in Wittgenstein's sense; it is in principle intelligible to us all - even if, when Marianna first coins the word, we do not yet know what it means. If there is a Wittgensteinian argument against the possibility of Marianna's setting up the word 'senso' in the way Papineau describes, therefore, the argument will not turn on considerations specific to the post- $\$ 243$ argument against a private sensation language. The point must be that Marianna's attempt to coin the word 'senso' violates general constraints on setting up any word with a meaning. So the question is this: is there enough in Marianna's act of inward-looking ostensive definition for her to succeed in setting up the word 'senso' or the concept $\Psi$ ?

Wittgenstein insists that, if I am to succeed in setting up a word (or a concept), there must be some answer to the question, 'What kind of thing am I naming?', 'What is going to count as the same kind of thing again?' From Wittgenstein's point of view, whether those questions have a satisfactory answer in Marianna's case depends on exactly how we fill out the details of the case. Suppose Marianna's position is this. She knows that she has seen a slip of coloured paper for the first time. She also knows that colours can be individuated in different ways: both coarsely (e.g. red, green, blue, yellow), and finely (e.g. crimson, scarlet, vermillion, ruby). When she coins the concept $\Psi$ to pick out experiences of the kind she has just had, what she intends to pick out is a coarsely-individuated kind of colour-experience. Given that background, Wittgenstein's requirement is met; there is no Wittgensteinian objection to the idea that Marianna succeeds in establishing a genuine concept. On the other hand, suppose that Marianna sees a piece of red paper and thinks 'That's a $\Psi$ experience', but that there is nothing at all to determine which, of the many candidate concepts she could in the circumstances have set up, is the one she has actually established: she herself has no answer at all to the question, what kind of experience her new concept is intended to 
apply to (other than simply to repeat that the concept is intended to pick out experiences of the same kind as the one she had when she introduced it); nor does she have any ability to recognize other experiences as similar to or different from this one; and so on. In that situation, Wittgenstein would say that Marianna has not succeeded in setting up a concept at all. And it is not just Wittgenstein who would say that. Many advocates of phenomenal concepts would take the same view. ${ }^{13}$

Papineau disagrees. In his view Marianna can, even in this situation, set up a new concept for herself by taking 'a potential experience concept' from an innate stock of potential concepts for types of experience, and 'lock[ing] it onto the type of experience at hand. Nothing more is needed’ (Papineau 2011, 182). So Marianna can successfully attach the concept $\Psi$ to a definite kind of experience on the basis of the kind of one-off, internal ostension envisaged in the second case. As Papineau says, Wittgenstein would reject that model of how concepts are established. But, though Papineau develops his account of phenomenal concepts in a way that involves the model, the phenomenal concept view is not itself committed to it. We can accept the idea that there are phenomenal concepts - and we can accept that, given the right surroundings, Marianna could successfully establish her concept $\Psi$ - without accepting Papineau's model of how concepts are established. In particular, I have argued, the existence of phenomenal concepts, and the possibility of Marianna's concept $\Psi$, are quite compatible with Wittgenstein's view of thought and language in general, and with his discussion of sensation language in particular.

\section{5. 'Mustn't I know what it would be like if I was in pain?'}

At PI $\S \S 448-9$, Wittgenstein explicitly considers the suggestion that understanding the word 'pain' requires knowing what it would be like if I were in pain. He writes:

If someone says, 'For the word "pain" to have a meaning, it is necessary that pain should be recognized as such when it occurs' - one can reply: 'It is not more necessary than that the absence of pain should be recognized.'

'But mustn’t I know what it would be like if I were in pain?' - One can’t shake oneself free of the idea that using a sentence consists in imagining something for every word.

One fails to bear in mind the fact that one calculates, operates, with words, and in due course transforms them into this or that picture. - It is as if one believed that a written order for a cow, which someone is to hand over to me, always had to be accompanied by a mental image of a cow if the order was not to lose its sense (PI §§448-9).

The second paragraph of this passage seems hostile to the suggestion that understanding the word 'pain' requires knowing what it would be like if I were in pain. And the first paragraph seems hostile to the particular way in which we have fleshed out that suggestion: the idea that grasping the concept pain requires the ability to recognize pain when one feels it. So it is tempting to think that Wittgenstein is here rejecting the idea that there is a way of thinking of pain that is available only to those who know what it is like to feel pain. But that would be too quick.

In the first place, Wittgenstein's main target in this passage is the idea that using and understanding words requires mental imagery. The reason he rejects the suggestion that understanding the word 'pain' requires knowing what it would be like if I were in

13. For example, that will be the view of those who hold that grasping a phenomenal concept involves the ability to recognize experiences as falling under the concept. For views of that sort, see e.g. Loar 1997, Levin 2007, Peacocke 2009, chapter 5. 
pain is that he takes it as an expression of the imagist view that understanding the word 'pain' requires me to imagine being in pain. And, of course, he rejects the imagist view. But, as I have emphasized, we do not have to understand the idea of knowing what it is like to feel pain in terms of the ability to imagine pain. We can understand it in terms of the ability to recognize pain when one feels it. What Wittgenstein is really rejecting, then, is not the 'knowing what it is like' requirement itself; it is a specifically imagist reading of that requirement.

It might be thought, however, that Wittgenstein explicitly rejects the proposal that grasping the concept pain requires being able to recognize pain as such when one feels it. For in the first paragraph just quoted, he responds with scepticism to the similar suggestion (tailored to words rather than concepts) that "For the word "pain" to have a meaning, it is necessary that pain should be recognized as such when it occurs'. 'It is not more necessary' that pain should be recognized as such, he says, 'than that the absence of pain should be recognized'. And that response certainly implies some kind of disagreement with the original suggestion.

However, I do not think we should take Wittgenstein's response as a rejection of the current proposal about the concept pain. For one thing, Wittgenstein himself endorses an analogue of that proposal for the case of understanding the word 'pain'; he thinks that someone cannot understand the word 'pain' if she does not have the ability to self-ascribe pain when she has it. He writes:

if someone said 'I don't know if what I have is a pain or something else', we should think, perhaps, that he does not know what the English word 'pain' means; and we'd explain it to him. ... .

If he now said, for example, 'Oh, I know what "pain” means; what I don't know is whether this, that I have now, is pain' - we'd merely shake our heads and have to regard his words as a strange reaction which we can't make anything of (PI §288).

The implication of that passage is that if someone knows what 'pain' means, she must in general know whether or not a sensation she is currently having is a pain. ${ }^{14}$ And that just is the condition that she must recognize pain as such when she has it. (It is consistent with what Wittgenstein says that someone can understand the word 'pain' without having being infallible about when he is in pain. He might honestly think that he is in pain when he is not. (That is sometimes true of hypochondriacs. ${ }^{15}$ ) And he might doubt whether some sensation on the borderline between pain and something else is or is not a pain. ${ }^{16}$ )

What point is Wittgenstein making, then, in the first paragraph of the passage quoted above from PI §448-9? The passage comes in an extended discussion of intentionality, dealing among other things with the relation between an order and its execution, a wish and what satisfies it, an expectation and its fulfilment, and so on. At an early stage in the discussion, Wittgenstein says this:

The agreement, the harmony between thought and reality consists in this: that if I say falsely that something is red, then all the same, it is red that it isn't. And in this: that if I want to explain the word 'red' to someone, in the sentence 'That is not red', I do so by pointing to something that is red (PI §429).

14. Wittgenstein himself would object to the idea that I know whether or not my sensation is a pain. (He thinks that that way of talking implies - wrongly - that I observe my sensation, that I find out about it on the basis of evidence, and so on.) But for present purposes, nothing turns on that. The points I make in the text could be equally well expressed in an idiom more acceptable to Wittgenstein.

15. For other cases, see Churchland 1988, 76-7, and Williamson 2000, 14.

16. For cases like this, see Tye 2009, 64-5. 
Seen in that context, part of the point of the passage (which is adapted with minor changes from Philosophical Remarks 113-14) is to stress that ' $\mathrm{S}$ is in pain' and ' $\mathrm{S}$ is not in pain' come as a pair: to understand the meaning of one is to understand the meaning of both. (As Wittgenstein puts it in Philosophical Remarks, “Pain” means, so to speak, the whole yardstick and not one of its graduation marks' (PR 114).) But of course that is not something that the phenomenal concept view denies.

Another part of the point of PI §448 is plausibly to object to Russell’s Analysis of Mind view on which, as Wittgenstein puts it, 'there are three [things involved in the fact that a thought is true], i.e. thought, fact and a third event which, if it occurs, is just recognition' (PR 63) ${ }^{17}$. 'This third event', writes Wittgenstein - the 'recognition' 'could, for example, be a feeling of pleasure' (ibid.). On Russell's view, Wittgenstein says, 'if I give someone an order and I am happy with what he then does [i.e. I recognize his action as fulfilling my order], then he has carried out my order' (PR 64); if I have a feeling of desire or dissatisfaction, and getting an apple produces a feeling of pleasure (i.e. I recognize an apple as being what I wanted), then it was an apple that I desired. Applying the same principles to the present case, the Russellian suggestion would be that what makes the word 'pain' true of a particular sensation is a feeling of fitting or appropriateness: an act of recognizing the sensation as falling under the word 'pain'. But, Wittgenstein argues, that view is absurd. Now Wittgenstein is certainly discussing this Russellian view about 'events of recognition' in parts of the discussion around $\S \S 448-9$. (See, for example, PI $\S \S 440$ and 460.) It is plausible to think that his response to the suggestion that, "for the word "pain" to have a meaning, it is necessary that pain should be recognized as such when it occurs', is similarly directed at the Russellian view, with its explanation of intentionality in terms of events of recognition. But the Russellian view is quite different from the view that the ability to recognize one's pains as such is a condition for grasping the concept pain. So Wittgenstein is not here rejecting the view of the concept pain that we are considering.

\section{Recognizing a Sensation as Pain}

In order to grasp the concept pain, I have said, one must be able to recognize one's own pain as such when one feels it. It might be objected that the idea of recognizing or identifying one's own sensations as pains is thoroughly unWittgensteinian, because it implicitly treats a subject's first-person use of sensation language as involving the observation and description of a realm of inner objects - which is precisely the view that Wittgenstein works so hard to undermine. Thus P.M.S. Hacker, for example, writes this:

one may in certain cases speak of recognizing (noticing, realizing) that another person is in pain. In one's own case [however], not only is it not necessary that one recognize one's pains when they occur, it is not even possible, for there is no such thing as recognizing that one is in pain (Hacker 2000, 68).

And James Hopkins identifies the view of sensations to which Wittgenstein is opposed as 'the recognitional conception', which involves 'constru[ing] sensations as objects of recognition' and treating the first-person use of mental words on the model of 'the use of words for items we perceptually recognize' (Hopkins 1974-5, 122).

It is certainly true that, in Wittgenstein's view, we do not observe our own sensations. And when I say 'I am in pain', he thinks, I do not 'identify my sensation by means of criteria’ (see PI §290); I do not classify my sensation as belonging to a

17. See also PR 111, where Wittgenstein comments on the related suggestion that 'the sense consists in the possibility of recognition'. 
particular category on the basis of its observed characteristics. I simply come out with the word 'pain' in response to my pain, without going through any process of identification or categorization. But we can accept that grasping the concept pain involves the ability to recognize one's own sensations as pains without committing ourselves to that model. Someone who grasps the concept pain has the following ability: she can self-ascribe pain when she has it, without inference, without observing her own behaviour, and without attending to the cause of her sensation. That is all we need for making sense of the idea of recognizing one's pains that is involved in the phenomenal concept view. And there is nothing in that to which Wittgenstein need object. $^{18}$

Similarly, grasping the phenomenal concept of tingling requires the ability to recognize or identify a sensation as an instance of tingling when one feels it, without inference or observation. What that involves is the ability to self-ascribe tingling sensations when one feels them, without inference or observation of one's behaviour or situation. I said above that someone may have a concept of tingling without having this ability: someone who has never had an electric shock may think of tingling as the sensation that is typically caused by a mild electric shock. If she then has an electric shock for the first time, and knows that she does, she may be able to identify the new feeling she has as a case of tingling. But at that stage, she is not self-ascribing tingling without inference or observation; she knows the sensation is a case of tingling because she knows its cause. It is only later, when she can reliably self-ascribe tingling sensations, and do so without inference, that she knows what tingling feels like and grasps the phenomenal concept of tingling. As before, there is nothing in what I have just said about the ability to recognize a sensation as an instance of tingling to which Wittgenstein should object. There is no suggestion that someone who self-ascribes tingling sensations when she feels them is observing her sensation; or that she identifies her sensation as an instance of tingling on the basis of criteria; or that she goes through any other intellectual process before saying, or judging, that she feels tingling. And what I have said is compatible with any reasonable sense in which the utterance 'I feel tingling' is an expression of sensation.

Treating knowing what an experience is like in the way I have outlined makes good sense of an interesting comment on the topic in Wittgenstein's late writings.

Can I teach the blind what seeing is, or can I teach this to the sighted? That doesn't mean anything. Then what does it mean: to describe seeing? But I can teach human beings the meaning of the words 'blind' and 'sighted', and indeed the sighted learn them, just as the blind do. Then do the blind know what it is like to see? But do the sighted know? Do they also know what it's like to have consciousness? (LW II 75. Also published as RC §279).

One strand in that passage and the related discussion is the suggestion that there is something wrong with the idea that sighted people know what it is like to see. We can see what might be wrong with that idea if we think of knowing what a sensation is like in the way I have suggested - as involving an ability to recognize or identify a sensation when one feels it.

In the case of pain, knowing what it's like to feel pain involves knowing what it is like to feel pain as opposed to not feeling pain. Correspondingly, the ability to recognize pain when one feels it is an ability to distinguish the case where one is in pain from the case where one is not. Similarly, knowing what tingling feels like involves

18. Wittgenstein might object to the idea that someone who says (or thinks) 'I am in pain' when she feels pain is 'self-ascribing pain', preferring to say that she is expressing her pain. In the present connection, I do not think anything turns on this point. 
knowing what it is like to have tingling feelings as opposed to not having them. And the ability to recognize tingling when one feels it is an ability to distinguish the case where one has tingling feelings from the case where one does not. Now Wittgenstein recognizes that we are inclined to think that sighted people know what it is like to see, and that blind people do not - just as people who have experienced tingling sensations generally know what tingling feels like, and people who have not do not. But, he thinks, the analogy does not go through. In order to know what it is like to see, one would have to know what it is like to see as opposed to being blind. But for sighted people, being sighted is part of the general condition of their life. We are not in a position to recognize cases where we are sighted as such - or to distinguish cases where we are sighted from cases where we are not. I speculate that that is why Wittgenstein suggests that it is wrong to think that the sighted know what it is like to see.

\section{Wittgenstein and the Individuation of Concepts}

It might still be objected that a Wittgensteinian approach to sensations and sensation language should reject the idea that there are distinctive phenomenal concepts of sensation, for reasons having to do with the individuation of concepts.

Any account of phenomenal concepts must say something about how concepts are individuated. What makes the concept of pain that is available to those who know what it is like to experience pain different from the concept (or concepts) of pain that can be grasped by people who do not? A standard answer appeals to the classic Fregean test of cognitive significance. As Peacocke puts it:

Concepts $\mathrm{C}$ and $\mathrm{D}$ are distinct if it is possible rationally to judge some content containing $\mathrm{C}$ without judging the corresponding content containing $\mathrm{D}$ (Peacocke 2009, 60).

So, for example, what makes the phenomenal concept tingling different from the descriptive concept of tingling that is available to someone who has never had an electric shock is the potential informativeness of learning that sensations of this kind (identified using the phenomenal concept tingling) are the sensations that are typically caused by an electric shock.

However, some philosophers have worried that the test of cognitive significance will carve concepts of experience more finely than seems plausible by any intuitive, notion of sameness of concept. If we share that worry, we may be tempted to abandon the idea that there are distinctive concepts of experience that are available only to those who know what the relevant experiences are like, and individuate concepts of experience in some more coarse-grained way. One possibility is a view defined by the following three principles:

(i) Someone grasps the concept pain if and only if she understands the word "pain" (or its equivalent in another language).

(ii) She understands the word "pain" just in case she is a sufficiently fluent participant in the practice of using the word. ${ }^{19}$

(iii) She can understand the word 'pain', by this standard, even if she has never experienced pain and doesn't know what it would be like to experience it.

A view of that sort is often ascribed to Wittgenstein. And that ascription has considerable plausibility. Condition (i) - which associates grasping a concept with understanding a word - chimes with much that Wittgenstein says: for example, his

19 For this way of putting things, see Williamson 2007, chapter 4. 
comment that 'a concept is a technique of using a word' (LPP 50). ${ }^{20}$ Condition (ii) is a way of capturing Wittgenstein's idea that grasping the meaning of a word is a matter of grasping its use. And some commentators, at least, think that Wittgenstein evidently accepts condition (iii). Hacker, for example, writes in his exegesis of PI §315 that 'we do not have a rule that prohibits saying of a person that he knows what "pain" means if, although he uses it correctly, he has never suffered pain' (Hacker 1993, 145); a person with CIPA could understand the word 'pain' as well as the rest of us.

In recent work, Michael Tye adopts precisely this kind of view (see Tye 2009, chapter 3.6). 'The concepts we apply introspectively to what it is like for us', he says, 'do not require for their possession that we have undergone the relevant experiences' (Tye 2009, 69). On Tye's view, someone who has never felt pain can grasp the same concept of pain as the rest of us; when she uses the word 'pain' she expresses the same thoughts as the rest of us. Of course, she lacks some abilities that we have; in particular, the ability to recognize an experience as a pain just on the basis of the experience. But a difference in recognitional abilities, Tye thinks, does not imply a difference in concepts. After all, 'an expert can be very good at recognizing elm trees by sight; I am not. Thus, the expert has a perceptual, recognitional ability I lack’ (Tye 2009, 72). The expert 'knows much more than me about elm trees - his conception of elms (that is, the cluster of beliefs he associates with the concept $\mathrm{elm}$ ) is much richer than mine.' But, according to Tye, that does not mean that the expert's concept elm is different from mine. On the contrary, 'intuitively we both share a thought with the same content when we say "that is an elm” on the basis of our respective perceptual experiences' (Tye 2009, 72-3).)

Despite the Wittgensteinian resonances of this view, however, it would be wrong to think that Wittgenstein is committed to individuating concepts in this relatively coarse-grained way rather than in the more fine-grained style of the phenomenal concept view. We can see that in two ways: by looking at cases where he talks about there being different concepts of such-and-such; and by thinking about his background conception of sense.

In some cases where Wittgenstein talks of two people (or groups of people) having 'different concepts of F', the different concepts he has in mind are not different ways of thinking of the same property. Instead, they pick out different properties; it is possible for one concept to be true of something that the other concept is not true of. For example, he says 'one could imagine a concept of fear that ... applied only to beasts, and therefore pertained only to behaviour' (RPP II §333). He describes the imagined concept as a concept of fear. But it is not a different way of thinking of the property picked out by our concept fear; it picks out a different (though overlapping) property. Similarly, Wittgenstein talks of there being different concepts of experience. It is a 'logical condition' of someone's having certain experiences, he says, that she should have mastered a certain technique. (An example would be: seeing now this, now that, as the apex of a triangle.) For other experiences, there is no such condition. ('You don't say that one "has toothache" only if one is capable of doing such-and-such' (PPF $\S 223$ [PI II xi p. 208].) 'From this', Wittgenstein says, 'it follows that we cannot be dealing with the same concept of experience here' (ibid.). But these 'different concepts of experience' are concepts that pick out different kinds of experience; they are not different ways of picking out the same experiences. Or again, Wittgenstein describes circumstances that would incline us to say that two different people had different concepts of 'reddish': one concept allows for the possibility of reddish green; the other

20 This passage is quoted by Schulte 2010, 128; and by Glock 2010, 103. Glock's paper offers an extended account of Wittgenstein's view of concepts that is in line with condition (i). 
concept does not (RC III 30). Once more, these different concepts of reddish pick out different, though overlapping, properties.

However, Wittgenstein also talks about 'different concepts of F' in cases where, intuitively, the different concepts do pick out the same property. He suggests, for example, that there could be different concepts of a minor chord: a purely structural concept, which was 'used solely to describe a perceived structure'; and the ordinary musical concept, which incorporates a minor chord’s ‘emotive value’ (PPF §226). These different concepts would pick out the same chords; but they would pick them out in different ways. Examples like that suggest that Wittgenstein's views can certainly make room for the idea there are different concepts of pain in the sense required by the phenomenal concepts view: different ways of thinking of the same property, pain.

There is a similar ambivalence in Wittgenstein's attitude to such questions as 'Can someone who has never felt fear mean by the word "fear" what we mean by it?', or 'Do blind and sighted people mean something different by the words "blind" and "sighted"?' He recognizes a sense in which one can understand these words without having had the relevant experiences. But he also recognizes a sense in which one cannot understand the words, or at least, understand them in the same way as us, without having the experiences. ${ }^{21}$ So it is not as clear as some have thought that Wittgenstein endorses condition (iii) above.

Wittgenstein's view of the individuation of concepts ultimately turns on his conception of sense. What is that conception? Two sentences' having the same sense, he suggests, consists in their having the same use (see PI §20). But what does it take for two sentences to have the same use? For Wittgenstein, there is no single, canonical standard of sameness of use. Two sentences may count as having the same use (and, therefore, the same sense) by one standard but as having a different use (and a different sense) by another (see PI §§531-2, 561-8, and BB 104 for examples and discussion). And, he thinks, there is no need to choose between the two standards: they are equally legitimate; and neither is more fundamental or more philosophically significant than the other. It fits well with that view to hold that there are different and equally legitimate ways of individuating concepts, between which there is no philosophical need to choose. In particular, there is a legitimate way of individuating concepts on which the word 'pain', as used by different speakers, may express different concepts while picking out the same property. Does the person with CIPA, who does not know what pain feels like, have the same concept of pain as the rest of us, who do? Well, is her use of the word 'pain' the same as our use of the word? By one standard, it is. She, like us, is a competent participant in the practice of using the English word 'pain'. She uses 'pain' to pick out a conscious experience, which can be self-ascribed immediately and without inference by those who experience it. And the word 'pain', on her lips, applies to all and only the things to which the word 'pain' applies on our lips. But by another standard her use of the word is different from ours: she cannot apply the word 'pain' to a sensation in the distinctively first-person way that is possible for the rest of us - she cannot recognize a felt experience as a pain; and her application of the word 'pain' to others has no link to feelings with which she is herself familiar. That difference gives a real point to saying that the person with CIPA has a different concept of pain from the rest of us - even though, for other purposes, and adopting a different standard of concept-individuation, we may say that she grasps the same concept of pain as we do.

21 See in particular the discussion at RPP II §26-8. For reasons of space, I cannot explore those remarks, and the broader issue they raise, here. But I plan to discuss them in future work. 
On Wittgenstein's approach, there is no need to choose between these different standards of sameness of concept; they are both legitimate.

\section{Conclusion}

Should we conclude that the existence of phenomenal concepts is consistent with a Wittgensteinian treatment of sensations and sensation language?

I would put matters like this. We can accept that there is a distinctive concept of pain, available only to those who know what it is like to feel pain, whilst accepting a Wittgensteinian view of sensations. In particular, the idea that there is such a concept of pain does not commit us to the possibility of a private sensation language. It does not commit us to any kind of imagism about thought, or to the idea that we observe our own sensations. And it is compatible with Wittgenstein's approach to the individuation of concepts. The notion of a phenomenal concept that emerges is rather different from the notion that some advocates of phenomenal concepts have proposed. But, from a Wittgensteinian perspective, it is a worthwhile and defensible notion. ${ }^{22}$

22. Successive drafts of some of this material have been presented at conferences at the University of California Santa Cruz in 2008, the British Wittgenstein Society in 2009, the University of Southampton in 2010, and Kings College London and the Maison Française d'Oxford in 2011; and also at the Universities of Keele and Manchester. I am grateful to the participants on those occasions for many helpful comments; and to Christopher Peacocke and Paul Standish for subsequent correspondence. 
W Child - "Wittgenstein and Phenomenal Concepts”, in M. Campbell and M. O’Sullivan, eds, Wittgenstein and Perception, Abingdon: Routledge, pp. 84-103.

\section{References}

Works by or originating from Wittgenstein:

BB: The Blue and Brown Books.

LPP: Lectures on Philosophical Psychology.

LW I: Last Writings on Philosophy of Psychology, Volume I.

LW II: Last Writings on Philosophy of Psychology, Volume II.

PI: Philosophical Investigations, $4^{\text {th }}$ edition.

PPF: 'Philosophy of Psychology: A Fragment', in Philosophical Investigations (a.k.a. Philosophical Investigations Part II).

PR: Philosophical Remarks.

RC: Remarks on Colour.

RPP I: Remarks on the Philosophy of Psychology, Volume I.

RPP II: Remarks on the Philosophy of Psychology, Volume II.

Z: Zettel.

Other works:

Alter, T. and Walter, S. (eds.) 2007: Phenomenal Concepts and Phenomenal Knowledge, Oxford: Oxford University Press.

Balog, K. 2009: 'Phenomenal Concepts' in B. McLaughlin et al (eds.), The Oxford Handbook of Philosophy of Mind, Oxford: Oxford University Press, 2009.

Churchland, P. 1988: Matter and Consciousness, revised edition, Cambridge, Mass.: MIT Press.

Conee, E. 1994: 'Phenomenal Knowledge', Australasian Journal of Philosophy, 72, 136-50.

Dennett, D. 2007: 'What RoboMary Knows', in Alter and Walter 2007.

Glock, H-J. 2010: 'Wittgenstein on Concepts', in A. Ahmed (ed.) Wittgenstein's Philosophical Investigations: A Critical Guide, Cambridge: Cambridge University Press.

Hacker, P. M. S. 1993: Wittgenstein: Meaning and Mind, Volume 3 of an Analytical Commentary on the Philosophical Investigations, Part II: Exegesis, Oxford: Blackwell.

Hacker, P. M. S. 2000: Wittgenstein: Mind and Will, Volume 4 of an Analytical Commentary on the Philosophical Investigations, Part II: Exegesis, Oxford: Blackwell.

Hopkins, J. 1974-5: 'Wittgenstein and Physicalism', Proceedings of the Aristotelian Society, 75, 121-46.

Levin, J. 2007: 'What Is a Phenomenal Concept?', in Alter and Walter 2007.

Lewis, D. 1988: 'What Experience Teaches', in Proceedings of the Russellian Society, Sydney: University of Sydney; reprinted in Lycan 1990, 499-518.

Loar, B. 1997: 'Phenomenal States (Second Version)', in N. Block et al (eds.), The Nature of Consciousness, Cambridge, Mass.: MIT Press; reprinted in D. Chalmers (ed.) Philosophy of Mind: Classical and Contemporary Readings, Oxford: Oxford University Press, 2002.

Lycan, W. (ed.) 1990: Mind and Cognition, Oxford: Blackwell. 
W Child - “Wittgenstein and Phenomenal Concepts”, in M. Campbell and M. O’Sullivan, eds, Wittgenstein and Perception, Abingdon: Routledge, pp. 84-103.

Nemirow, L. 1990: Physicalism and the Cognitive Role of Acquaintance, in Lycan 1990, 490-99.

Nida-Rümelin, M. 1996: 'What Mary Couldn’t Know', in T. Metzinger (ed.) Phenomenal Consciousness, Paderborn, Germany: Schoenigh.

Nida-Rümelin, M. 1998: 'On Belief about Experiences: An Epistemological Distinction Applied to the Knowledge Argument', Philosophy and Phenomenological Research, 58, 51-73.

Papineau, D. 2011: 'Phenomenal Concepts and the Private Language Argument', American Philosophical Quarterly, 48:2, 175-84.

Peacocke, C. 2009: Truly Understood, Oxford: Oxford University Press.

Russell, B. 1921: The Analysis of Mind, London: Allen and Unwin.

Schulte, J. 2010: 'Concepts and Concept-Formation', in N. Venturinha (ed.) Wittgenstein after his Nachlass, Basingstoke: Palgrave Macmillan.

Tye, M. 2009: Consciousness Revisited, Cambridge, Mass.: MIT Press.

Williamson, T. 2000: Knowledge and Its Limits, Oxford: Oxford University Press.

Williamson, T. 2007: The Philosophy of Philosophy, Oxford: Blackwell. 